\title{
PENERAPAN TEKNOLOGI WINDROW COMPOSTING BAGI MASYARAKAT SEKITAR TPA MUARA FAJAR PEKANBARU
}

\author{
Ida Zahrina, dan Elvi Yenie \\ ${ }^{1}$ Program Studi Teknik Kimia, Jurusan Teknik kimia, Fakultas Teknik, Universitas Riau \\ ${ }^{2}$ Program Studi Teknik Lingkungan, Jurusan Teknik kimia, Fakultas Teknik, Universitas Riau \\ Email: ida.zahrina@eng.unri.ac.id
}

\begin{abstract}
ABSTRAK. Volume sampah organik yang cukup besar di TPA Muara Fajar dapat dimanfaatkan oleh warga sekitarnya dengan mengolahnya menjadi kompos. Selain dapat memperpanjang umur TPA, kegiatan pengomposan ini juga dapat meningkatkan perekonomian masyarakat. Oleh karena, perlu adanya kegiatan pengabdian kepada masyarakat sekitar TPA Muara Fajar agar memiliki ketrampilan dalam mengolah sampah organik menjadi kompos dengan teknologi windrow composting. Teknologi ini cocok diterapkan bagi warga sekitar TPA Muara Fajar karena dapat diaplikasikan untuk semua jenis sampah organik, loading capacity yang besar, serta menghasilkan kompos dengan kualitas yang baik. Kegiatan ini diikuti oleh warga RT 01 RW 03 Kelurahan Muara Fajar, Pekanbaru melalui sosialisasi, penyuluhan, pelatihan serta evaluasi. Dari kegiatan ini, masyarakat telah mampu memproduksi kompos dari sampah organik. Namun masih perlu kegiatan pengabdian lanjutan untuk membentuk unit usaha kompos di masyarakat.
\end{abstract}

Kata kunci: pelatihan dan pendampingan; pengomposan windrow; sampah organik; TPA

ABSTRACT. The Muara Fajar landfill has a large volume of organic waste. It's can be utilized by the surrounding residents by processing it into compost. This composting activity is able to extend the life of the landfill and also improve the community's economy. Therefore, it is necessary to have community service activities around the Muara Fajar landfill in order to have skills in processing organic waste into compost using windrow composting. This technology is suitable for residents around the Muara Fajar landfill because it can be applied to all types of organic waste with a large loading capacity, and also produces good quality compost. This activity was attended by residents of RT 01 RW 03 Muara Fajar Village, Pekanbaru with the following stages: socialization, counseling, training and evaluation. From this activity, the community has been able to produce compost from organic waste. However, further community service activities are still needed to form a compost business unit in the community.

Keywords: landfill; organic waste; training and mentoring; windrow composting

\section{PENDAHULUAN}

TPA (Tempat Pembuangan Sampah Akhir) kota Pekanbaru berlokasi di RT 01 RW 03 Kelurahan Muara Fajar Kecamatan Rumbai. Jumlah sampah di TPA Muara Fajar terus meningkat setiap tahunnya, seperti ditampilkan pada Gambar 1.

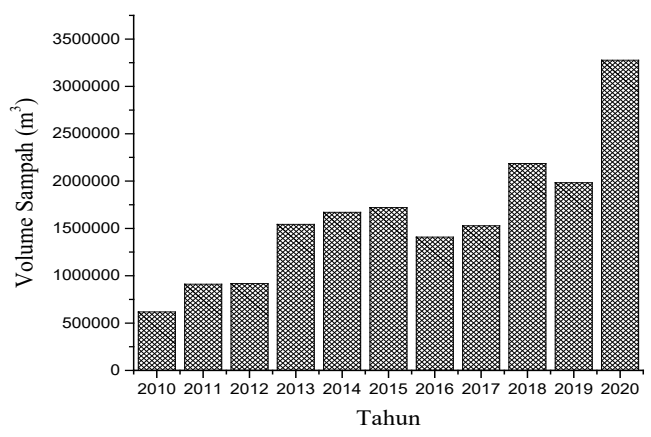

Gambar 1. Volume sampah di TPA Muara Fajar Pekanbaru tahun 2010 - 2020 (Dinas Lingkungan Hidup dan Kebersihan Kota Pekanbaru, 2020)

Dari total volume sampah tersebut, sebanyak $70 \%$ merupakan sampah organik (Puspa, 2017). Sampah-sampah organik yang berasal dari pasarpasar yang ada di kota Pekanbaru hanya sebagian diolah menjadi pupuk kompos di unit composting. Jumlah sampah organik di kota Pekanbaru yang terus meningkat setiap tahun ini mengakibatkan unit composting yang ada di TPA Muara Fajar tidak mampu mengolah seluruh sampah organik tersebut.

Masyarakat sekitar TPA Muara Fajar memiliki peluang yang besar untuk memanfaatkan sampahsampah organik ini sebagai bahan baku pembuatan kompos. Kompos tersebut bisa dimanfaatkan sebagai pupuk pada lahan pertanian warga serta dapat meningkatkan perekonomian masyarakat di Kelurahan Muara Fajar.

Dalam proses pengomposan akan diperoleh kompos sebanyak 1/3 dari bahan bakunya (sampah organik). Jika masyarakat mengolah sampah organik sebanyak 2 ton setiap harinya secara kontinu, maka akan diperoleh kompos sebanyak $700 \mathrm{~kg} /$ hari. Keuntungan bersih yang diperoleh dari usaha pengomposan sebesar Rp. 60 - 1.060 per kg (Djaja, 2010), sehingga keuntungan yang akan diperoleh sebesar Rp. 42.000 - 742.000 setiap harinya.

Menurut Kurnia et al. (2017), pengomposan sistem windrow cocok dengan kondisi Indonesia karena fleksibilitasnya. Kelebihan sistem windrow composting yaitu cocok diaplikasikan untuk semua jenis sampah organik, loading capacity yang besar, serta menghasilkan kompos dengan kualitas yang baik (Lim et al., 2017). Oleh karena itu, metode windrow composting cocok diterapkan untuk 
mengolah sampah organik di TPA Muara Fajar yang memiliki volume yang cukup besar. Unit composting di TPA Muara Fajar telah menerapkan metode windrow composting ini, namun hanya mampu mengolah sebagian kecil dari sampah organik yang ada, yaitu sekitar 0,04\% (Puspa, 2017). Oleh karena itu perlu adanya kegiatan pengolahan sampah organik ini melalui pemberdayaan masyarakat.

Melalui kegiatan pengabdian ini diharapkan masyarakat di Kelurahan Muara Fajar memiliki pengetahuan serta ketrampilan dalam mengolah sampah organik dengan teknologi windrow composting menjadi kompos dengan kualitas sesuai SNI. Selain dapat meningkatkan perekonomian masyarakat, kegiatan ini juga dapat memperpanjang umur TPA bila dilakukan secara berkesinambungan.

\section{METODE}

Kegiatan pengabdian ini diikuti oleh kelompok tani sayur di Kelurahan Muara Fajar, Pekanbaru. Kegiatan ini dilaksanakan di TPA Muara Fajar pada bulan Juli-Agustus tahun 2010. Tahapan pelaksanaan kegiatan pengabdian ini ditampilkan pada Gambar 2.

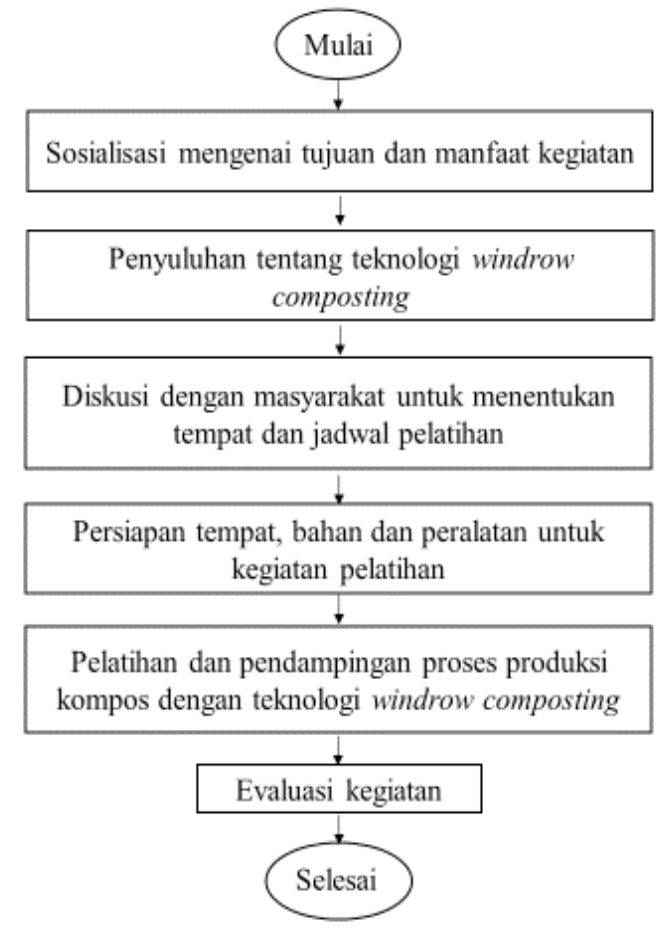

Gambar 2. Tahapan kegiatan pengabdian kepada masyarakat Kelurahan Muara Fajar Pekanbaru

Tahapan pelaksanaan kegiatan pengabdian ini adalah sebagai berikut:

1. Sosialisasi kegiatan pengabdian

Kegiatan pengabdian ini diawali dengan sosialisasi kepada masyarakat mengenai tujuan dan manfaat kegiatan pengabdian. Dengan sosialisasi ini diharapkan masyarakat termotivasi untuk memanfaatkan sampah organik yang jumlahnya sangat berlimpah di TPA Muara Fajar dengan mengolahnya menjadi kompos guna meningkatkan perekonomian.

2. Penyuluhan

Penyuluhan dilakukan dengan cara menjelaskan kepada masyarakat mengenai proses pengomposan yang akan dilakukan.

3. Persiapan tempat, alat dan bahan

Pengomposan dilakukan di atas lantai semen yang ditutupi dengan atap dari terpal. Bahan-bahan yang digunakan pada kegiatan pengabdian ini yaitu sampah organik TPA Muara Fajar dan bioaktivator (kompos dan ragi tempe). Peralatan yang diperlukan berupa plastik terpal, alat pencacah sampah secara manual, termokopel, $\mathrm{pH}$ meter, plastik kemasan transparan.

\section{Pelatihan}

Teknologi windrow composting yang diterapkan bagi masyarakat sekitar TPA Muara Fajar ini mengacu pada prosedur yang telah dipublikasi pada beberapa buku referensi, yaitu Isroi dan Yuliarti (2009) dan Murbandono (2010).

\section{Evaluasi kegiatan}

Evaluasi kegiatan pengabdian ini dilakukan melalui pengamatan langsung dengan penilaian kinerja dalam proses persiapan dan pelaksanaan. Untuk menentukan tingkat keberhasilan pelatihan ini, evaluasi dilakukan menggunakan indikator yang tercantum pada Tabel 1.

Tabel 1. Check list proses evaluasi kegiatan

\begin{tabular}{|c|c|c|c|c|c|}
\hline \multirow{2}{*}{ No } & \multirow{2}{*}{ Indikator } & \multicolumn{4}{|c|}{ Skala Nilai } \\
\hline & & 4 & 3 & 2 & 1 \\
\hline 1. & $\begin{array}{l}\text { Memahami langkah-langkah } \\
\text { pengomposan }\end{array}$ & & & & \\
\hline 2. & $\begin{array}{l}\text { Ketrampilan mencacah dan pembalikan } \\
\text { sampah }\end{array}$ & & & & \\
\hline 3. & Ketrampilan pemakaian aktivator & & & & \\
\hline 4. & $\begin{array}{l}\text { Ketrampilan mengukur suhu dan } \mathrm{pH} \\
\text { kompos }\end{array}$ & & & & \\
\hline
\end{tabular}

\section{HASIL DAN PEMBAHASAN}

Pelatihan pembuatan kompos di TPA Muara Fajar diikuti oleh warga RT 01 RW 03 Kelurahan Muara Fajar, Pekanbaru. Sampah yang diolah menjadi kompos adalah sampah yang berasal dari pasar-pasar yang ada di kota Pekanbaru.

Pada kegiatan pelatihan ini, sampah yang diolah sebanyak $200 \mathrm{~kg}$ sampah sayuran dan buahbuahan, dengan tahapan sebagai berikut.

1. Pemilahan sampah

Walaupun bahan baku kompos berasal dari sampah pasar yang dominan adalah sampah organik, namun perlu dilakukan pemilahan sampah anorganik yang terikut seperti plastik (Gambar 3a). 


\section{Pengecilan ukuran sampah}

Masyarakat melakukan proses pengecilan ukuran (mencacah) sampah (Gambar 3b). Pengecilan ukuran sampah bertujuan untuk memperluas permukaan area bahan agar proses pengomposan berlangsung lebih cepat akibat meningkatnya kontak antara mikroba dengan bahan organik. Ukuran partikel juga menentukan porositas di dalam tumpukan bahan kompos yang akan mempengaruhi pasokan oksigen untuk proses pengomposan.
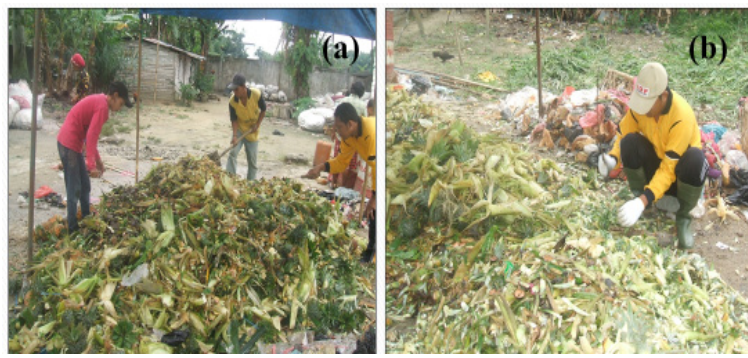

Gambar 3. Masyarakat melakukan pemilahan sampah (a) dan mencacah sampah (b)

\section{Penambahan bioaktivator}

Aktivator atau biang kompos mengandung mikroba yang dapat mempercepat proses pengomposan serta meningkatkan kualitas kompos yang dihasilkan. Pada pelatihan ini digunakan 2 aktivator yaitu kompos dan ragi tempe (Gambar 4).

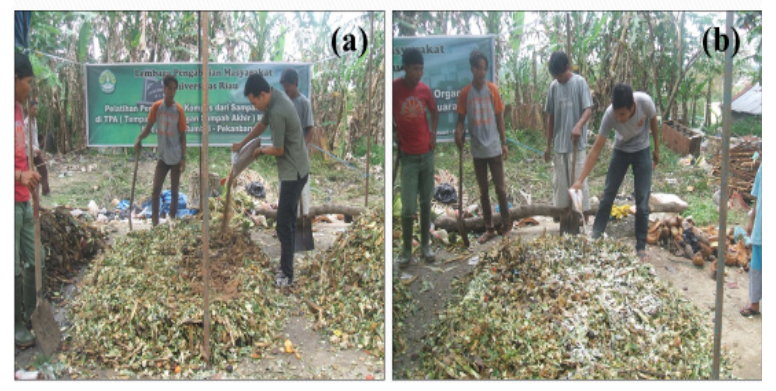

Gambar 4. Masyarakat melakukan penambahan aktivator kompos (a) dan ragi tempe (b)

\section{Pengadukan dan penutupan sampah}

Pengadukan sampah setelah pemberian aktivator bertujuan agar aktivator merata ke seluruh sampah organik sehingga proses pengomposan juga berlangsung secara merata dalam sampah organik. Selanjutnya sampah organik ditutup dengan plastik berlubang untuk menjaga kelembaban. Kelembaban sangat mempengaruhi proses metabolisme mikroba.
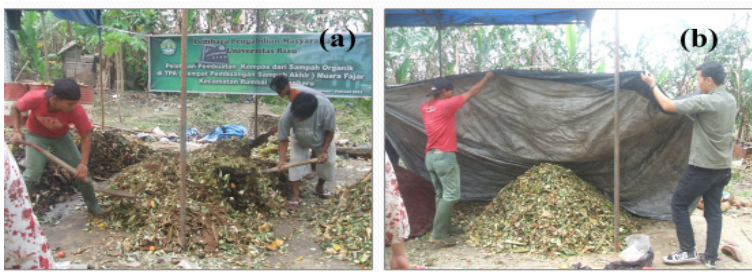

Gambar 5. Masyarakat melakukan pengadukan sampah setelah penambahan bioaktivator (a) dan menutupnya (b)

\section{Pengukuran suhu dan $\mathrm{pH}$}

Suhu dan $\mathrm{pH}$ sangat mempengaruhi proses pengomposan. Oleh karena itu, suhu dan $\mathrm{pH}$ dikontrol tiap 5 hari sekali agar proses pengomposan dapat berlangsung lebih cepat, lebih baik serta menghasilkan kompos dengan kualitas yang baik (Gambar 6a).

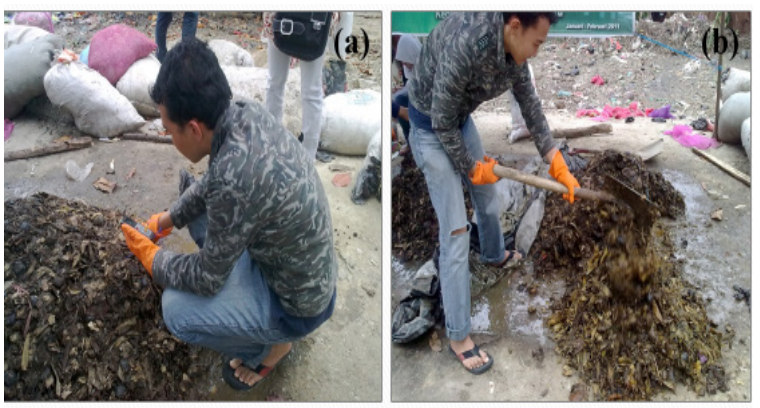

Gambar 6. Masyarakat melakukan pengukuran suhu dan pH kompos pada hari ke-10 (a) dan melakukan pembalikan kompos (b)

\section{Pembalikan sampah selama pengomposan}

Pembalikan bahan kompos juga dilakukan tiap 5 hari sekali untuk meningkatkan aerasi (Gambar 6b). Apabila aerasi terhambat, maka akan terjadi proses anaerob sehingga akan menghasilkan bau yang tidak sedap.

\section{Pengeringan dan pengayakan kompos}

Kompos yang telah matang ditandai dengan bau seperti tanah dan berwarna coklat kehitaman. Kompos dikeringkan dengan menjemur di bawah sinar matahari. Selanjutnya dihaluskan dan diayak untuk memisahkan bahan-bahan organik yang tidak terkomposkan dengan sempurna. Produk kompos hasil pelatihan ini disajikan pada Gambar 7.

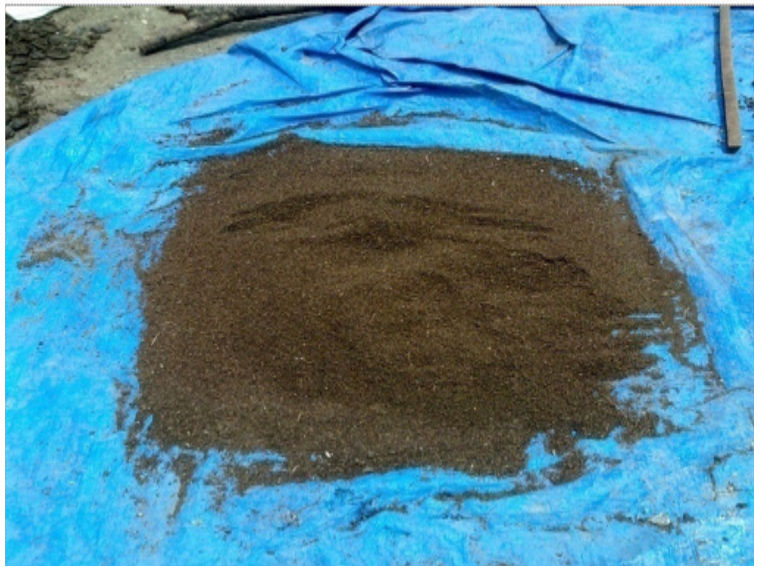

Gambar 7. Produk kompos yang dihasilkan

\section{Pengujian kualitas produk}

Agar produk kompos yang dihasilkan memenuhi kualitas (SNI 19-7030-2004), maka melalui pelatihan ini dilakukan analisa laboratorium untuk mengetahui unsur hara NPK kompos dari sampah organik di TPA Muara Fajar (Tabel 2). 
Tabel 2. Kadar NPK kompos dari sampah organik di TPA Muara Fajar

\begin{tabular}{cc}
\hline Komponen & Kadar $(\%)$ \\
\hline $\mathrm{N}$ & 0,750 \\
$\mathrm{P}\left(\mathrm{P}_{2} \mathrm{O}_{5}\right)$ & 2,340 \\
$\mathrm{~K}\left(\mathrm{~K}_{2} \mathrm{O}\right)$ & 0,018 \\
\hline
\end{tabular}

Kadar K pada kompos yang dihasilkan masih terlalu rendah. Agar produk kompos sesuai SNI, maka ditambahkan abu tandan kosong sawit untuk meningkatkan kadar K.

\section{Pengemasan}

Pengemasan dilakukan dalam kantong plastik transparan.

Evaluasi kegiatan ini dilakukan melalui pengamatan dan penilaian secara langsung terhadap ketrampilanyangtelahdimilikiolehwargamasyarakat selama kegiatan pelatihan dan pendampingan ini. Hasil evaluasi kegiatan pengabdian ini disajikan pada Tabel 3. Terlihat bahwa masyarakat telah memahami langkah-langkah pengomposan sampah organik dengan sangat baik. Hal ini juga terlihat dari produk kompos yang dihasilkan (Gambar 7). Selain itu, masyarakat juga sudah sangat terampil dalam mencacah sampah, pemakaian aktivator maupun pembalikan sampah. Namun, ketrampilan mengukur suhu dan $\mathrm{pH}$ kompos masih memiliki nilai pada skala 3. Hal ini disebabkan masyarakat belum pernah menggunakan alat ukur tersebut sebelumnya. Tindak lanjut yang dilakukan untuk meningkatkan ketrampilan mengukur suhu dan $\mathrm{pH}$ kompos adalah dengan menggunakan alat ukur digital sehingga proses pengukuran menjadi lebih mudah dan cepat.

Tabel 3. Hasil evaluasi kegiatan

\begin{tabular}{clc}
\hline No & \multicolumn{1}{c}{ Indikator } & $\begin{array}{c}\text { Nilai } \\
\text { Skala }\end{array}$ \\
\hline 1. & Memahami langkah-langkah pengomposan & 4 \\
2. & Ketrampilan mencacah dan pembalikan sampah & 4 \\
3. & Ketrampilan pemakaian aktivator & 4 \\
4. & Ketrampilan mengukur suhu dan $\mathrm{pH}$ kompos & 3 \\
\hline
\end{tabular}

\section{SIMPULAN}

Dari kegiatan pengabdian ini dapat disimpulkan bahwa melalui kegiatan pengabdian ini masyarakat di sekitar TPA Muara Fajar Pekanbaru khususnya RT 01 RW 03 telah memiliki ketrampilan untuk mengkonversi sampah organik TPA Muara Fajar menjadi pupuk kompos dengan teknologi windrow composting. Selanjutnya perlu adanya kegiatan pelatihan dan pendampingan untuk membentuk usaha pengomposan baik skala mikro maupun makro di kalangan masyarakat. Selain itu juga perlu adanya penerapan teknologi tepat guna (TTG) alat pencacah sampah organik agar proses pencacahan sampah bisa lebih singkat.

\section{UCAPAN TERIMAKASIH}

Penulis menyampaikan terimakasih kepada DP2M Dikti yang telah mendanai kegiatan pengabdian kepada masyarakat ini melalui hibah Program Ipteks bagi Masyarakat (IbM) tahun anggaran 2010.

\section{DAFTAR PUSTAKA}

Djaja, W. 2010. Langkah Jitu Membuat Kompos dari Kotoran Ternak dan Sampah. Jakarta: PT. Agromedia Pustaka.

Isroi dan Yuliarti, N. 2009. Kompos. Cara Mudah dan Cepat Menghasilkan Kompos. Yogyakarta: CV. Andi Offset.

Kurnia, V.C., Sumiyati, S. dan Samudro, G. 2017. Pengaruh Kadar Air Terhadap Hasil Pengomposan Sampah Organik dengan Metode Open Windrow. Jurnal Teknik Mesin. 6. 119-123.

Lim, L.Y., Bong, C.P.C., Lee, C.T., Klemeš, J.J., Sarmidi, M.R. dan Lim, J.S. 2017. Review on the Current Composting Practices and the Potential of Improvement using TwoStage Composting. Chemical Engineering Transactions. 61. 1051-1056.

Murbandono, L. 2010. Membuat Kompos. Depok: Penebar Swadaya.

Puspa, B.B. 2017. Life Cycle Inventory Untuk Pengelolaan Sampah Yang Berkelanjutan Di Kota Pekanbaru. Jurnal Planologi Unpas. 4(1). 819-826. 